Research Article

\title{
Fatigue Life Assessment of Orthotropic Steel Deck with UHPC Pavement
}

\author{
Xu Jiang, Yuan Yuan, Chong Wu, and Chengwei Luo \\ College of Civil Engineering, Tongji University, Shanghai, China \\ Correspondence should be addressed to Chong Wu; cwu@tongji.edu.cn
}

Received 12 October 2016; Revised 15 February 2017; Accepted 19 February 2017; Published 11 April 2017

Academic Editor: José A. F. de Oliveira Correia

Copyright (C) $2017 \mathrm{Xu}$ Jiang et al. This is an open access article distributed under the Creative Commons Attribution License, which permits unrestricted use, distribution, and reproduction in any medium, provided the original work is properly cited.

In recent years, a number of large-span bridges with orthotropic steel decks were constructed in China. With increasing traffic volumes and higher wheel loads, many fatigue cracks developed at the welds and the edge of cut-out holes. This paper aims at presenting the numerical analysis on the fatigue performance of the orthotropic steel deck using ultrahigh performance concrete (UHPC) overlay as the deck pavement instead of the conventional asphalt concrete pavement. By using finite element method (FEM) model, stress distribution at fatigue sensitive locations under the action of wheel loads is characterized and the obtained stress ranges indicate that the UHPC pavement significantly reduces the magnitude of the stress peak valued. A suggested truck stream model based on the weigh-in-motion (WIM) data of four bridges in China is employed to calculate the stress variation at specific fatigue details. Furthermore, the fatigue damage accumulation at fatigue details under the UHPC and conventional asphalt concrete pavement is studied based on Miner's linear cumulative damage rule and the rain-flow method. The results indicate that the UHPC pavement on the orthotropic steel deck can extend the service lives of the concerned regions over 100 years, but the fatigue lives will reduce significantly when the elastic modulus of UHPC decreases to $50 \%$ of the original value.

\section{Introduction}

Orthotropic steel decks are widely used in large-span steel bridges for many advantages: comparatively lightweight, thin structural depth, and high load capacity [1]. However, cracks can gradually be developed in the steel deck leading to a deteriorated state. For example, regular inspections performed since 2003 in the HuMen Bridge in China (Figures 1 and 2) have identified many cracks in the orthotropic steel deck [2]. And the pavement deterioration is as serious as the fatigue problems of the orthotropic steel deck. The pavement in some bridges cannot satisfy the serviceability, and in this situation, it has to be replaced with a new pavement.

In this paper, a new pavement method (UHPC overlay) is proposed, aiming to reduce the stress range in the orthotropic steel deck. The stress distribution in the orthotropic steel deck with the new pavement and the conventional asphalt concrete pavement is studied. The asphalt concrete exhibits a viscoelastic material behaviour, and its elastic modulus is sensitive to temperature variation, which shows an exponential function relationship by tests in laboratory [3]. The cement-based material is a better option compared with the conventional pavement, because its elastic modulus keeps steady when temperature changes. However, the disadvantages of the cement-based material are obvious. It increases the dead load and is prone to develop cracks.

Much research in recent years has focused on adopting the cement-based material layer as pavement. Shao et al. [4] proposed a composite bridge deck system comprised of $45 \mathrm{~mm}$ reactive powder concrete (RPC) overlay and $20 \mathrm{~mm}$ asphalt overlay. Through the finite element modeling analysis, the reduction of the peak transverse stress in deck (perpendicular to the span direction) was about $60 \%$ 70\%, compared with the value of axle load acting on the deck without pavement. Then the new pavement system was proved to be feasible in practice by a full-scale model test. Wang and Zhang [5] measured the practical stress variation of the orthotropic steel deck of a steel bridge in two cases: one was the test load directly acting on the steel deck without pavement, and the other was the test load acting on the super toughness concrete (STC) deck system (50 mm STC overlay and $20 \mathrm{~mm}$ asphalt overlay). The stress of the rib-to-deck connection 


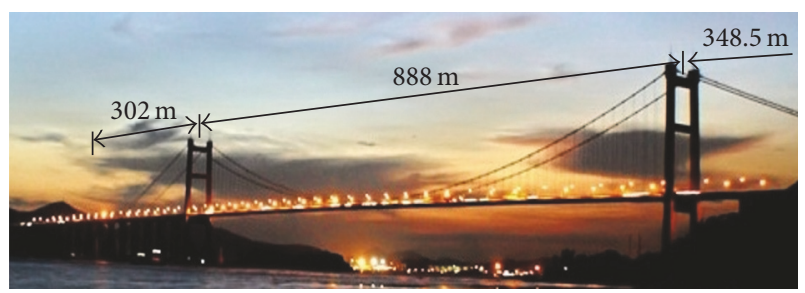

Figure 1: Configuration of the HuMen suspension bridge.

region could decrease by $70 \%$ with the STC overlay, and the stress at the weld of rib-to-diaphragm also decreased by $26 \%$. It should be noted that stress variation of the cut-out location was not notable. Dieng et al. [6] employed experimental and numerical methods to investigate stress reduction in the deck with the ultrahigh performance fiber reinforced concrete (UHPRFC) as the pavement. The maximum values of transverse strain at the rib-to-deck weld joint are reduced by $50 \%$, which is contributed by the $35 \mathrm{~mm}$ UHPRFC layer. The research of Walter et al. [7] aimed to analyze an orthotropic steel deck stiffened with the cement-based overlay based on the finite element method analysis. They investigated the performance of four overlay materials in terms of crack width, and numerous factors were taken into account such as shrinkage, temperature gradient, and traffic loading. The calculation results showed that the cement-based overlay may increase the dead load by $6.5 \%$, compared with the average dead load of common pavement, and the reduction of the stress peak value could be $80 \%$.

Previous works have mainly indicated that the stress reduction in the steel deck is dramatically effective with the cement-based materials casting on the deck as the pavement. In this study, the fatigue behaviour of the orthotropic steel deck of the HuMen Bridge (Figure 3) with a new proposed pavement method (UHPC layer) will be assessed based on the Miner's linear cumulative damage rule. A truck stream model is employed to calculate the fatigue damage accumulation at specific fatigue details.

\section{Background of the Bridge and the New Pavement}

The HuMen Bridge is located in the Pearl River Delta of Guangdong Province. This suspension bridge consists of three spans: the main span is $888 \mathrm{~m}$, the end spans are $302 \mathrm{~m}$ and $348.5 \mathrm{~m}$, respectively (Figure 1), and the height-to-span ratio is $1 / 10.5$. The steel box girder is $35.6 \mathrm{~m}$ width and $3.012 \mathrm{~m}$ depth at the symmetric axis of the section. The space between the diaphragms is $4 \mathrm{~m}$. Due to the underestimation of traffic load increasing in the early time, the adopted thickness of the steel deck was only $12 \mathrm{~mm}$, which is relatively thin from the viewpoint of modern design. The dimensions of the closed ribs (trapezoidal troughs) are $324 \mathrm{~mm} \times 262 \mathrm{~mm} \times$ $8 \mathrm{~mm}$, and the distance between the center of ribs is $620 \mathrm{~mm}$. At a design stage, full-penetration welds were demanded in the connection between the steel deck and the closed ribs.

Due to the deteriorated state of the original pavement (7 $\mathrm{cm}$ asphalt concrete), one proposed to replace it with a new pavement made of resin asphalt (RA05) and UHPC, as shown in Figure 4. According to the research report of Nanjing second bridge [8], the resilience modulus of RA05 is usually 3 times higher than the asphalt concrete, which is tested in the Jiangsu Transportation Institute, China.

The RPC mentioned in research of Shao et al. [4] is actually a kind of high-performance fiber concrete, the compressive strength is in the range of $170 \sim 230 \mathrm{MPa}$, and the elastic modulus is about $42.6 \mathrm{GPa}$. According to the introduction of the super tough concrete by Li et al. [9], the STC is a sort of modified RPC concrete with dense steel bars reinforced, and the elastic modulus of the STC is the same with the RPC. The compression strength of UHPRFC in Dieng et al.'s research [6] is about $100 \mathrm{MPa}$, and the elastic modulus of UHPRFC is $55 \sim 65 \mathrm{GPa}$. The UHPC in the proposed pavement in this study has a common advantage like the aforementioned materials: it has high tensile and compressive strength and exhibits good flowability so that it does not need to vibrate during casting. It is worth mentioning that this kind of UHPC does not need to be vapor-cured. The compression strength and tension strength of the UHPC are, respectively, $180 \mathrm{MPa}$ and $7 \mathrm{MPa}$ after a 28day curing period; other materials properties of the UHPC are listed in Table 1.

\section{FEM Model}

In order to investigate the stress distribution in the orthotropic steel deck, a substructural FEM model is established. The stress analysis is performed by the FEM software ANSYS version 12.1. A $24 \mathrm{~m}$ long segment of the girder in the $1 / 4$ main span is simulated with SHELL63, which is usually adopted to model the thin elastic plate. Other members of the bridge are modeled with BEAM188, and then the shell element model is coupled with the beam element model at the intersection. The bearings are idealized as simple supports, and the boundaries at the bottom of towers are fixed. The $7 \mathrm{~cm}$ thick pavement is simulated with the element SOLID 45 by sharing the common nodes with the shell elements of the deck. This assumption considers that the slippage between the pavement and steel deck is ignored. It is complicated to simulate the slippage accurately, so this simulation method is a compromise. In respect of Table 1, it is assumed that the elastic modulus of the UHPC is $45 \mathrm{GPa}$ and the elastic modulus of the RA05 and asphalt concrete is, respectively, $5000 \mathrm{MPa}$ and $1800 \mathrm{MPa}$. The orthotropic steel deck is made of Q345q grade steel with Young's modulus of $206 \mathrm{GPa}$. The mesh size of the shell model is $0.2 \mathrm{~m}$, while the refined mesh size for the concerned part is $0.01 \mathrm{~m}$. The stress variation related to the mesh size will be neglected when the mesh size is under $0.01 \mathrm{~m}$, and this has also been proven by Ji et al. [10].

\section{Transverse Stress Distribution in the Deck}

The wheel load $70 \mathrm{kN}$, according to the Chinese specification JTG D60-2004 [11], is placed on the deck in two positions (Figure 6). Both positions are centered on the top of closed rib. Load Case 1 is located at the diaphragm and Load Case 2 acts in the middle of the span between diaphragms. The steel 
TABLE 1: Material properties of the UHPC.

\begin{tabular}{lcccc}
\hline $\begin{array}{l}\text { Elastic modulus } \\
(\mathrm{GPa})\end{array}$ & $\begin{array}{l}\text { Density } \\
\left(\mathrm{kg} / \mathrm{m}^{3}\right)\end{array}$ & Poisson's ratio & Creep coefficient & $28 \mathrm{~d}$ shrinkage/10 \\
\hline $45 \sim 55$ & 2490 & 0.2 & 0.8 & $400 \sim 600$ \\
\hline
\end{tabular}

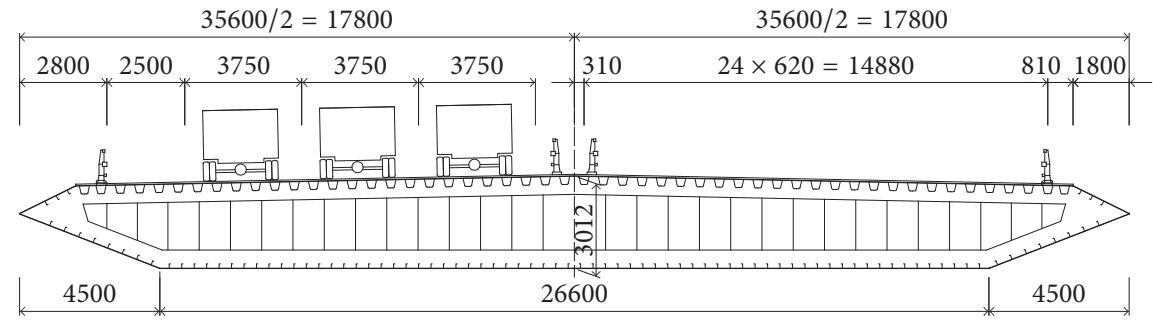

Figure 2: Cross-sectional view of the steel box girder of the HuMen Bridge (unit: mm).

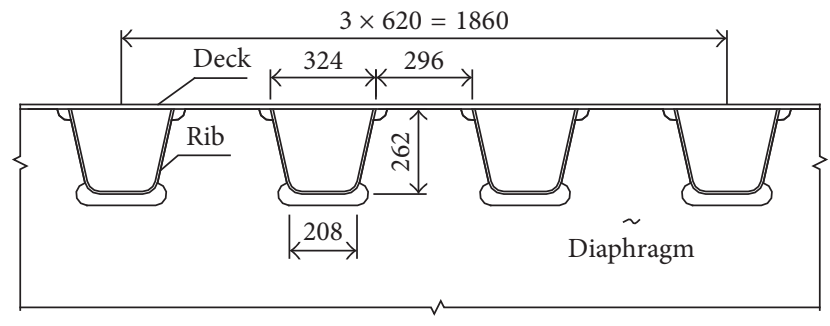

Figure 3: Details of the orthotropic steel deck of the HuMen Bridge (unit: $\mathrm{mm}$ ).

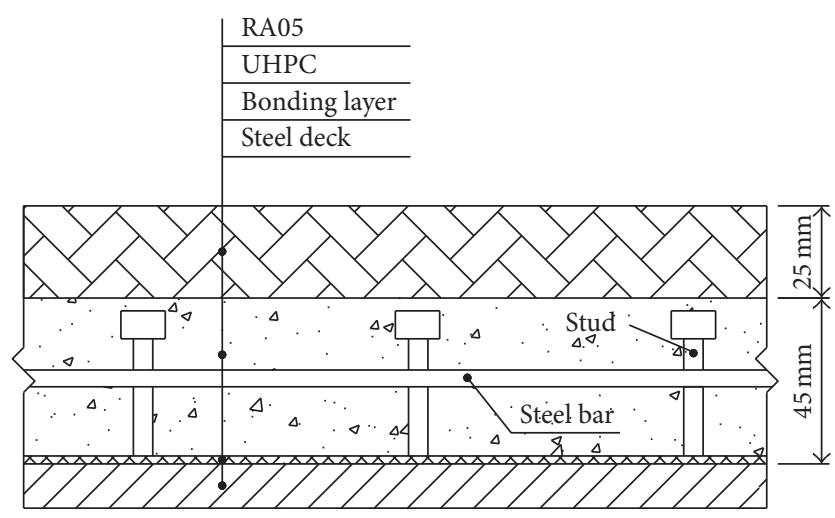

FIGURE 4: The proposed pavement method.

deck transverse stress distributions of the two sections under the wheel loads are analyzed.

Figure 7 shows the stress distribution comparisons of three cases: steel deck without pavement, steel deck with common asphalt concrete pavement, and steel deck reinforced with the proposed pavement. It is clear that the pavements have a significant effect on the stress distribution, especially the peak values of stress which are reduced obviously under the UHPC + RA05 pavement. The stress peak values of the deck bottom side with different pavements are compared in Table 2.
It should be noted that the stress concentration is severe in the region of the rib-to-deck weld. The majority of stress components are compressive at the bottom of the steel deck. As is known that, with the tensile residual stresses existing in the welded details, compressive cycling may also cause initial damage at the details [12]. Compared with Load Case 2 stress distribution of the deck in the middle span of diaphragms, the stress peak values of Load Case 1 are much higher, because the diaphragm constrains the rotation of closed ribs in the longitudinal direction. Theoretically, the rib-to-deck weld details at the diaphragm are more possible to suffer from fatigue cracks in contrast with the detail in other sections.

\section{Stress Influence Line}

Fatigue cracks tend to develop at locations of stress concentration. According to the stress distribution in the deck, there are six fatigue details concerned in this study (Figure 8), where fatigue cracks usually initiate and propagate [12].

The reference stress directions of the concerned details have been illustrated in Figure 8; the reference stresses still need to be clarified. In the present study, the nominal stress method is adopted to calculate the fatigue damage accumulation of the concerned details. For complex structural configurations, the finite element model is an effective way to catch the reference stresses (Figure 5), but the stress distributions near the weld connections are influenced by the stress concentration in FE model. According to the stress distributions in the shell elements in Figures 9(a) and 9(b), the bending stresses are dominant compared with the membrane stresses (the middle layer in the shell elements). Theoretically, the reference stresses in the thin steel plates belong to the structure stress, which is the combination of the bending stress and the membrane stress. Given that the reference stresses are the nominal stresses, Ji et al. [10] picked the point $10 \mathrm{~mm}$ away from the rib-to-deck weld to calculate the nominal stress. In this study, the points $5 \mathrm{~mm}$ away from the intersection of plates are selected to obtain the stress values for Details A, B, E, and F taking into account decreasing of the stress concentration of the weld connection in FE model. For Details C and D, the reference points 
TABLE 2: The transverse stress peak values of steel deck bottom side (unit: MPa).

\begin{tabular}{lccc}
\hline Load cases & No pavement & Asphalt pavement & UHPC+ RA05 pavement \\
\hline Load Case 1 & & & -0.1 \\
COR & 109.3 & 17.5 & -36.2 \\
RTD & -181.5 & -79.2 & 4.9 \\
\hline Load Case 2 & & & -12.8 \\
COR & 35.1 & 7.9 & -30.6 \\
RTD & -51.4 & & \\
\hline
\end{tabular}

COR means at center of rib; RTD means the rib-to-deck weld.

TABLE 3: The maximum stress ranges generated by dual tires unit wheel load.

\begin{tabular}{lccc}
\hline Details & Asphalt pavement & UHPC + RA05 pavement & Reduction percentage \\
\hline Detail A & 31.3 & 10.3 & $67.2 \%$ \\
Detail B & 56.9 & 9.8 & $82.9 \%$ \\
Detail C & 17.9 & 9.3 & $47.8 \%$ \\
Detail D & 28.7 & 21.4 & $25.4 \%$ \\
Detail E & 33.1 & 15.7 & $52.4 \%$ \\
Detail F & 9.2 & 3.2 & $65.6 \%$ \\
\hline
\end{tabular}

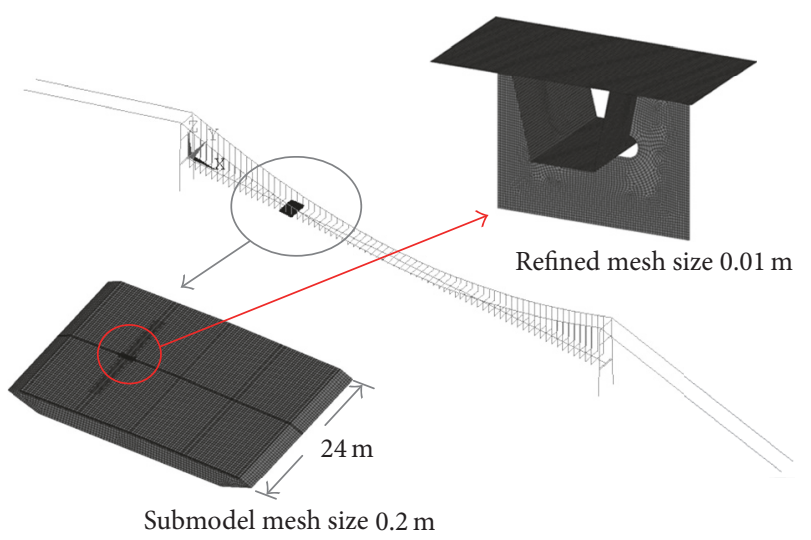

FIgURE 5: Substructural finite element model.

are located in the spots that are unfavorable of the stress distributions in Figure 9.

The reference stress influence lines of the concerned details will be calculated in the next process. Referring to the China General Code for Design of Highway Bridge and Culverts [11], a single tire contacting area is $0.2 \mathrm{~m} \times 0.3 \mathrm{~m}$, and the area of dual tires is $0.2 \mathrm{~m} \times 0.6 \mathrm{~m}$ (see Figure 10). The unit axle force is assumed to be $100 \mathrm{kN}$, so that the wheel load of both single tire and dual tires is $50 \mathrm{kN}$. As shown in Figure 11, there are 80 load steps in total, and each step of $0.2 \mathrm{~m}$ passes four spaces between diaphragms $(16 \mathrm{~m})$. The wheel load position on the shell element model riding the rib wall generates larger stress range at the fatigue details [13]. Thus, two stress influence lines for each investigated fatigue detail can be obtained after loading the single tire and dual tires.

Taking Detail B as an example (Figure 12), in comparison with the asphalt concrete pavement (AC pavement), the maximum stress range under the unit axle load is obviously
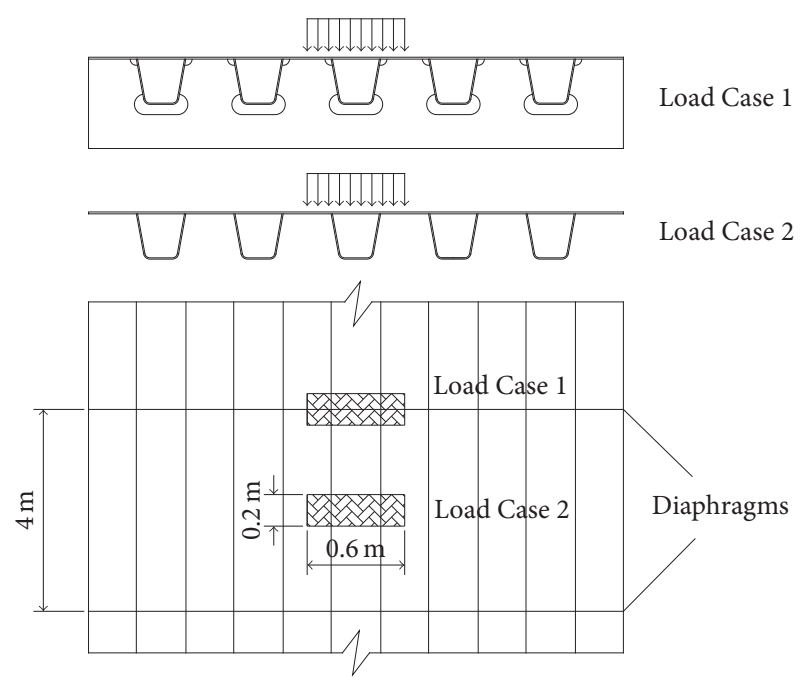

FIgURE 6: The wheel load positions on the steel deck.

reduced by $83 \%$ with the UHPC + RA05 pavement. The stress ranges of the concerned details generated by united wheel load are shown in Table 3. Expect for Detail C, the stress ratio $\left(\sigma_{\min } / \sigma_{\max }\right)$ is negative; the stress ranges of other details are all in compression. As mentioned above, though the stress ranges of the details are compressive cycles, the fatigue damage may still develop since the tensile residual stress exists in the regions of the welds. It should be noticed that Detail $\mathrm{D}$ belongs to the nonweld detail, the advantage of the beneficial effect that applied compressive stress should be taken into account. The stress range can be thus reduced by $40 \%$ in case of the stress range in compression [14]; namely, the stress ranges in Detail $\mathrm{D}$ can multiply a reduction factor 0.6 for the damage accumulation. 
TABLE 4: Traffic stream fatigue load.

\begin{tabular}{|c|c|c|c|}
\hline Vehicle type & $\begin{array}{c}\text { Truck } \\
\text { silhouette }\end{array}$ & $\begin{array}{c}\text { Axle span } \\
(\mathrm{m})\end{array}$ & $\begin{array}{c}\text { Axle load } \\
(\mathrm{kN})\end{array}$ \\
\hline \multirow[t]{2}{*}{$\mathrm{V}-2$} & & 4.5 & 50 \\
\hline & 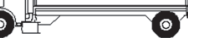 & & 100 \\
\hline \multirow{3}{*}{$V-3$} & & 4.5 & 50 \\
\hline & बि & 1.3 & 90 \\
\hline & & & 90 \\
\hline \multirow{4}{*}{$\mathrm{V}-4$} & & 3.2 & 50 \\
\hline & 10 & 6 & 100 \\
\hline & 00 & 1.3 & 90 \\
\hline & & & 90 \\
\hline \multirow{5}{*}{ V-5A } & & 3.2 & 50 \\
\hline & & 6 & 100 \\
\hline & 000 & 1.3 & 80 \\
\hline & & 1.3 & 80 \\
\hline & & & 80 \\
\hline \multirow{5}{*}{ V-5B } & & 3.2 & 60 \\
\hline & & 1.3 & 90 \\
\hline & 000 & 6 & 90 \\
\hline & & 1.3 & 90 \\
\hline & & & 90 \\
\hline \multirow{6}{*}{ V-6 } & & 3.2 & 60 \\
\hline & & 1.3 & 90 \\
\hline & 0000 & 6 & 90 \\
\hline & & 1.3 & 80 \\
\hline & & 1.3 & 80 \\
\hline & & & 80 \\
\hline
\end{tabular}

\section{Fatigue Load}

Based on traffic data from four bridges in China, in this work, a traffic stream fatigue load model is proposed [15]. The traffic stream fatigue model consists of sets of idealized standard trucks, which is surveyed by the typical traffic in China. The axle load and the axle span are listed in Table 4, and the impact factor is included in the axle load. There are six typical types of truck.

There are almost 6 months of available traffic data of the HuMen Bridge surveyed by a weigh-in-motion (WIM) system from 15 August 2008 to 31 January 2009. The traffic volume of the HuMen Bridge is divided into 6 parts according to the traffic stream fatigue load model. Taking the heavy vehicle lane (lane number 3 ) as an example, the amount of six vehicles in 6 months is schematically depicted in Figure 13.
The vehicle with two axles (V-2) occupies the most part of the traffic volume; however, the V-2 vehicle weights are basically below $10 \mathrm{t}$. Except the V-2 vehicle, the vehicle with four axles $(\mathrm{V}-4)$ represents the second largest amount of the total traffic data.

The stress influence lines of the details in steel deck are usually not long enough, so the vehicles can be equivalent to the axle loads without considering the axle loads sequence. The axle loads in the stream fatigue load model can be classified into four types (Table 5), which are single axle with two tires (A1-1), single axle with four tires (A1-2), double axle with eight tires (A2-2), and triaxle with twelve tires (A3-2). The stress histories of details can be generated by combining the axle loads and the stress influence lines, and then the stress ranges can be counted by the rain-flow method. 


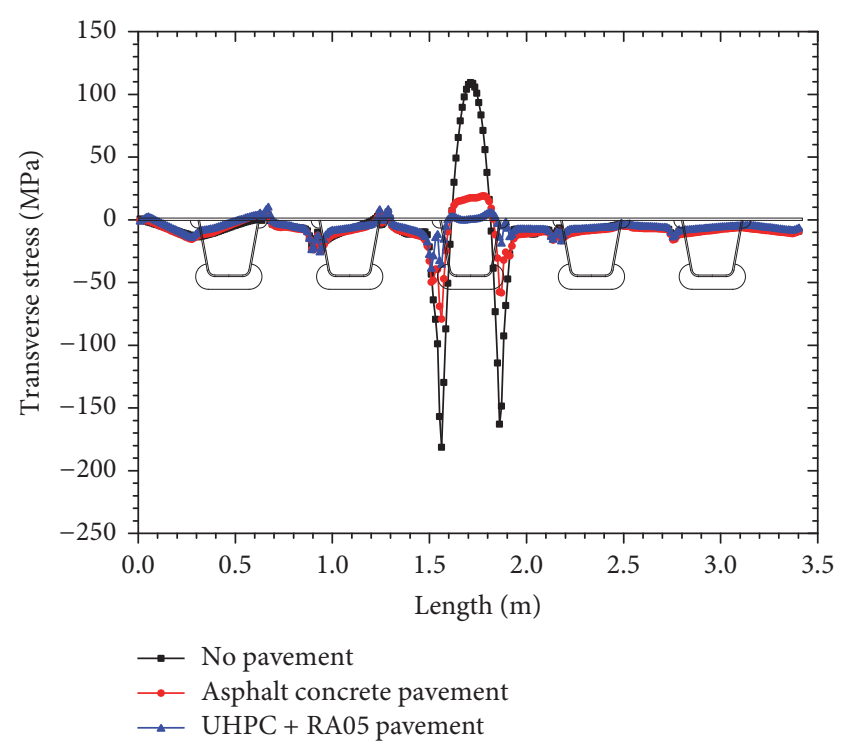

(a) Load Case 1

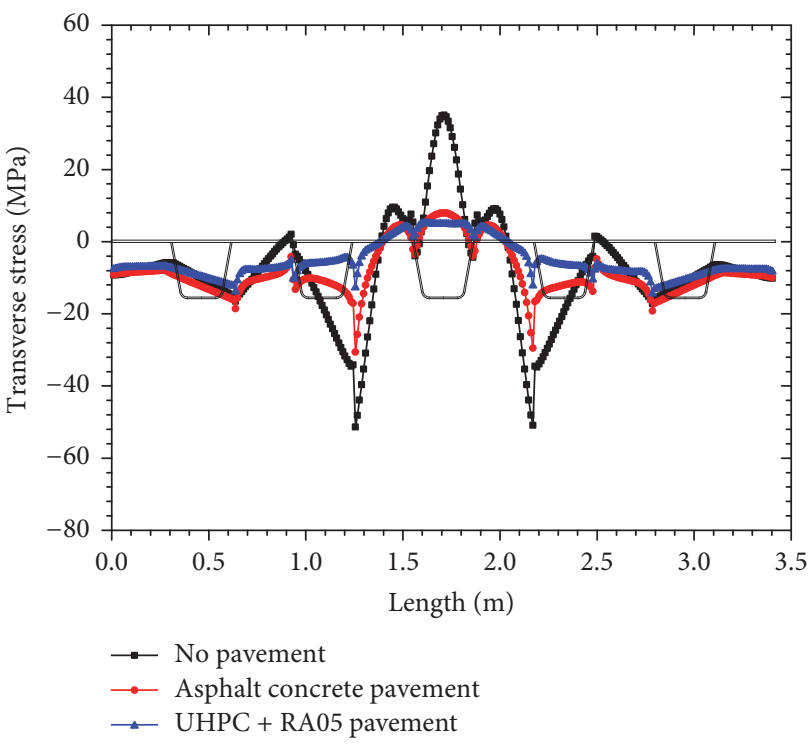

(b) Load Case 2

Figure 7: Stress distribution of the deck bottom side.

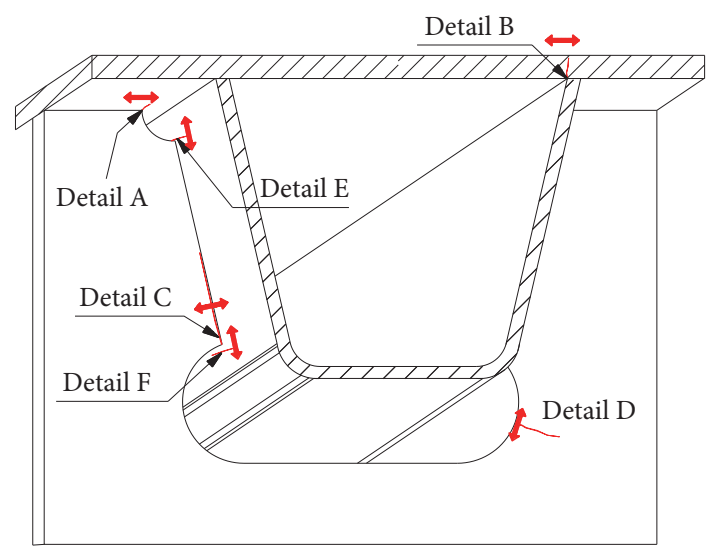

FIGURE 8: Crack modes of critical regions.

TABLE 5: Axle load in the stream fatigue load model.

\begin{tabular}{lcccc}
\hline Items & A1-1 & A1-2 & A2-2 & \multicolumn{2}{c}{ A3-2 } \\
\hline Axle type & & & & \\
Axles load (t) & 5.0 & 10.0 & $9.0+9.0$ & $8.0+8.0+8.0$ \\
\hline
\end{tabular}

\section{Fatigue Life Assessment}

Although the UHPC + RA05 pavement is designed to work without cracks, the decreasing of the elastic modulus due to cracks in the pavement still ought to be considered. The fatigue behaviour of UHPC is ambiguous and the fatigue test data are scatter [16]. According to test results of Makita and Brühwiler [17], cracks of UHPC will stop at about 500,000 cycles when the elastic modulus has reduced by
TABLE 6: Fatigue strength of details (MPa).

\begin{tabular}{lcccccc}
\hline Details & A & B & C & D & E & F \\
\hline Fatigue strength & 56 & 71 & 71 & 125 & 56 & 56 \\
\hline
\end{tabular}

$30 \%$. Yu et al. [18] conducted the fatigue test of the reactive powder concrete, which indicated a decrease of $50 \%$ in the original value of the elastic modulus before reaching to the fatigue damage. Therefore, for the sake of the conservative consideration, it is assumed that the elastic modulus of the UHPC pavement decreases to $0.5 E$ with cracks appearing, with $E$ being the original elastic modulus.

The fatigue life assessment will be conducted in three pavement cases, which are the common asphalt concrete, the $\mathrm{UHPC}+\mathrm{RA} 05$ pavement, and the UHPC + RA05 pavement with appearing cracks leading to a $50 \%$ decrease in the original value of elastic modulus of UHPC. Based on Miner's rule, the threshold value of the fatigue damage accumulation is equal to 1 :

$$
D=\sum \frac{n_{i}}{N_{i}} \leq 1
$$

where $n_{i}$ is the number of cycles corresponding to stress range due to axle loads on the deck. $N_{i}$ is the endurance (in cycles) corresponding to stress range and it can be obtained by the $\mathrm{S}-\mathrm{N}$ curve which is determined by the fatigue strength of the detail. The values of the fatigue strength have to refer to similar details in Eurocode 3 [19] due to lack of test data for the orthotropic steel deck. Fatigue details are categorized by the reference stress value $\Delta \sigma_{C}$ at 2 million cycles, for concerned fatigue details in this study; the fatigue categories are listed in Table 6.

The damage accumulation for each axle type can be calculated according to (1). Therefore, the contribution of 


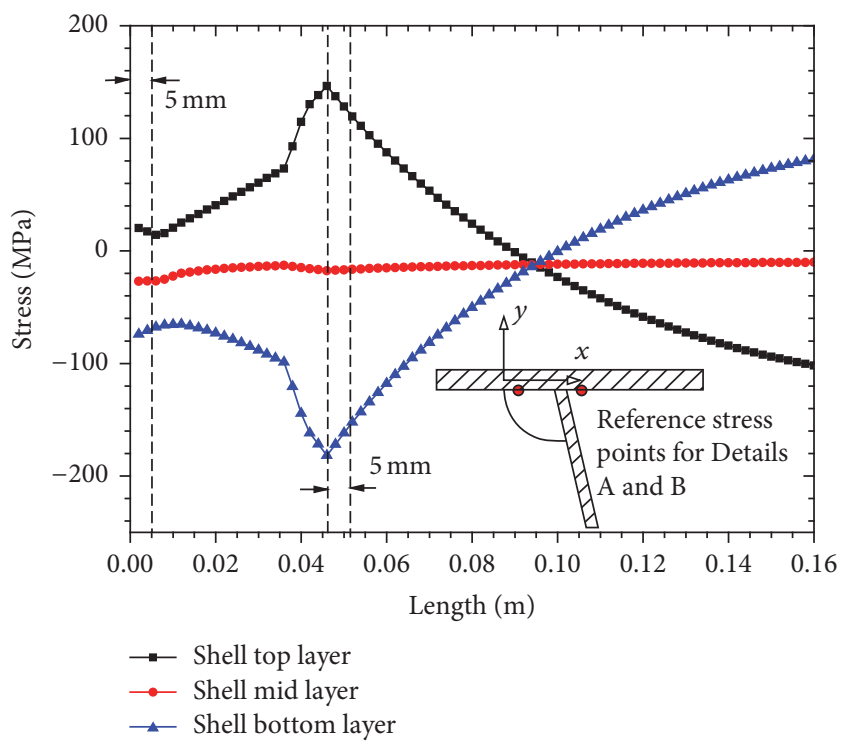

(a)

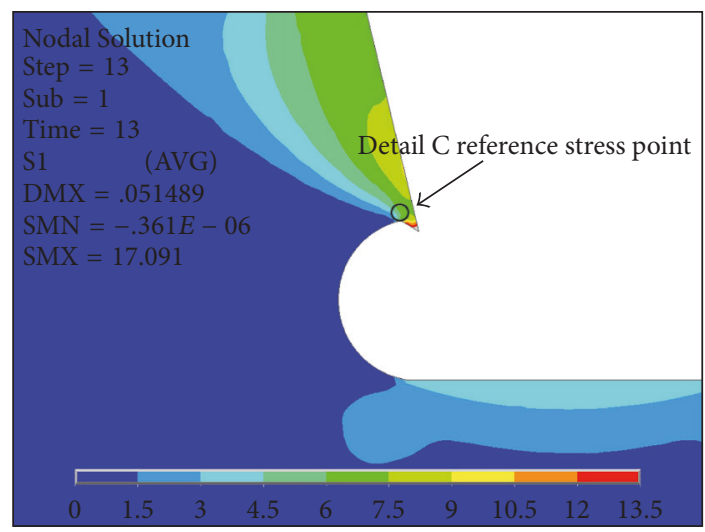

(c)

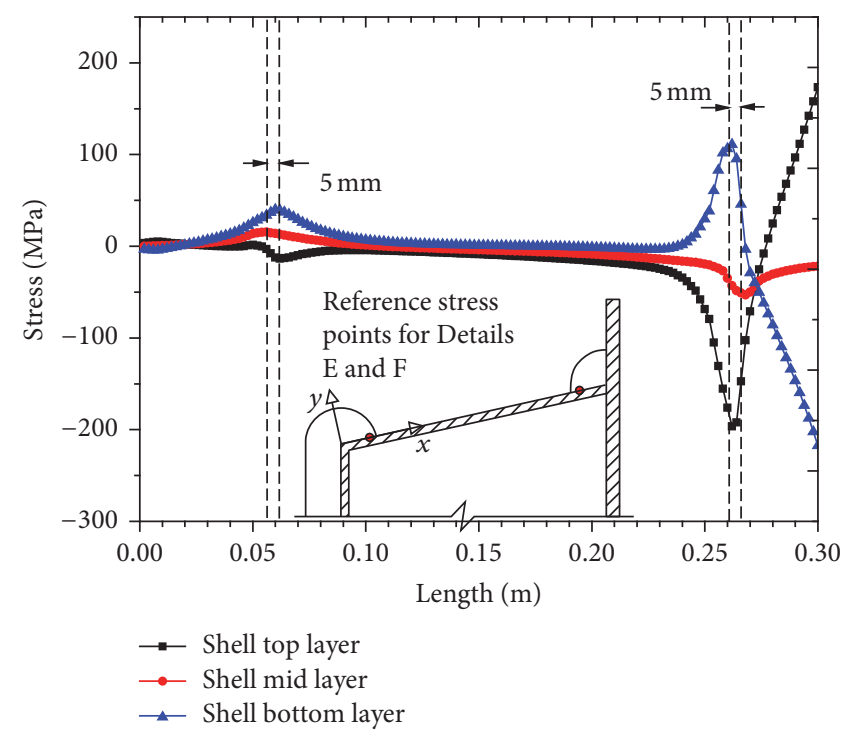

(b)

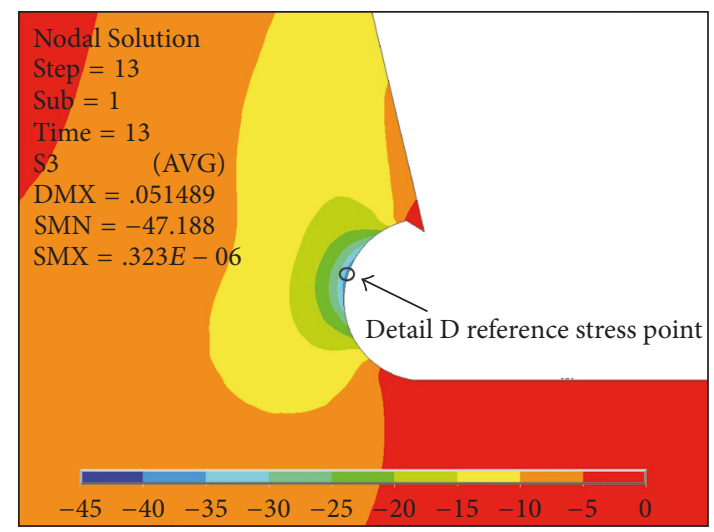

(d)

FIGURE 9: Reference stresses points of the concerned details in FE model.

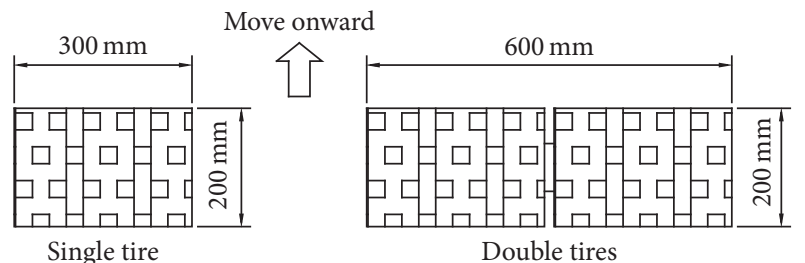

Figure 10: Areas of tires contacting the ground.

each truck from the traffic stream model for the fatigue damage is the total amount of accumulated damage of the belonging axle types. Given the condition that 6 months of statistical data can reflect the characteristics of the traffic volume of the whole year, the fatigue damage accumulation of one year can be obtained by multiplying the amount of trucks in Figure 13 with the damage accumulation per truck. Thus, fatigue lives are the reciprocal of damage accumulation, as illustrated in Figure 14.
The fatigue lives of Details A, B, and $\mathrm{E}$ with the common asphalt concrete pavement are very short. This is supposed to be that the three details are near the wheel load, resisting the tire pressure directly. The UHPC + RA05 pavement improves the fatigue lives of details significantly, with all the concerned fatigue lives exceeding over 100 years except Detail E, as its fatigue life can be improved by thickening the rib wall. Actually in modern design, the cope hole in the diaphragm of the rib-to-deck region has been avoided [19]. The fatigue lives decrease dramatically after reducing the elastic modulus by $50 \%$ due to cracks in the UHPC layer.

\section{Discussions}

The UHPC + RA05 pavement can reduce the stress range in most of critical areas, and it is an effective method to stiffen the orthotropic steel deck. However, cracks control in the cement-based material is the most difficult problem, which deserves more research in the future. In this section, a parametric study for Detail B is carried out. Three influence 

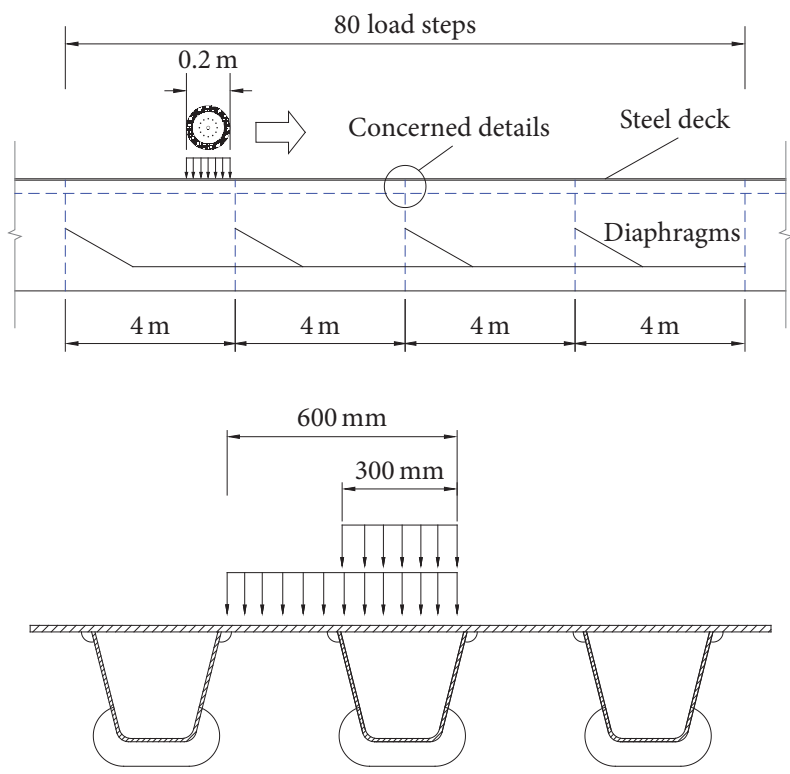

FIGURE 11: Loading steps on the deck for analyzing stress influence lines.

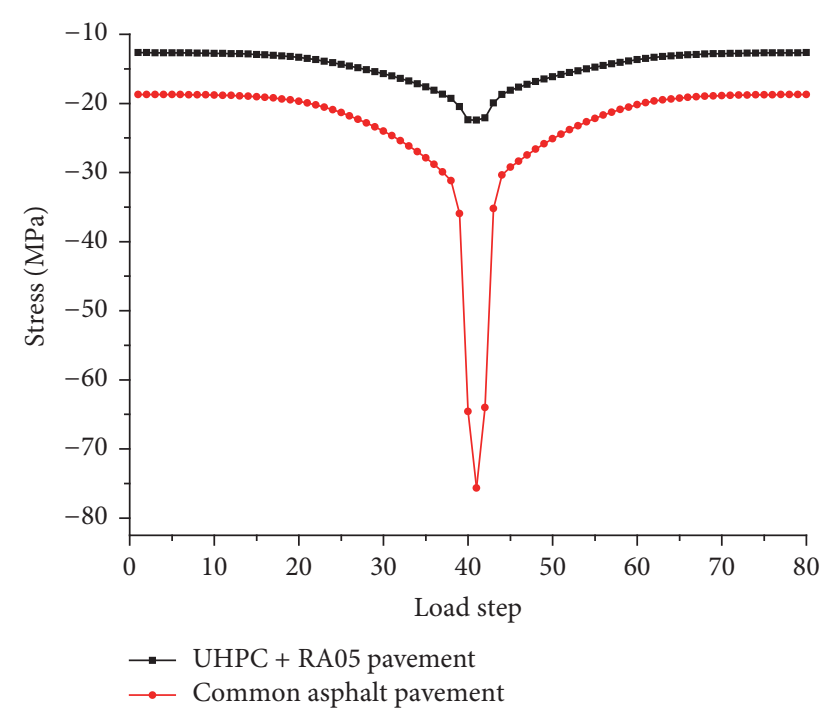

FIGURE 12: Stress influence lines of Detail B under the dual tires unit wheel load.

factors are investigated: (1) the asphalt concrete pavement thickness, (2) the elastic modulus of UHPC, and (3) the thickness of steel deck with the UHPC pavement. The thickness of the asphalt concrete pavement varies from $7 \mathrm{~cm}$ to $22 \mathrm{~cm}$, and reduction factors of elastic modulus of UHPC are selected to be $0.7,0.5,0.3$, and 0.1 . The thickness of the steel deck varies from $12 \mathrm{~mm}$ to $28 \mathrm{~mm}$. As indicated in the aforementioned results, Detail B is prone to develop cracks earlier than other details. The transverse stress variation of this region is the focus of analysis, and the load position and load weight are in the same conditions as shown in Figure 6.

In Figure 15(a), the transverse stress reduces from $56 \mathrm{MPa}$ to $40 \mathrm{MPa}$ when the common asphalt concrete pavement

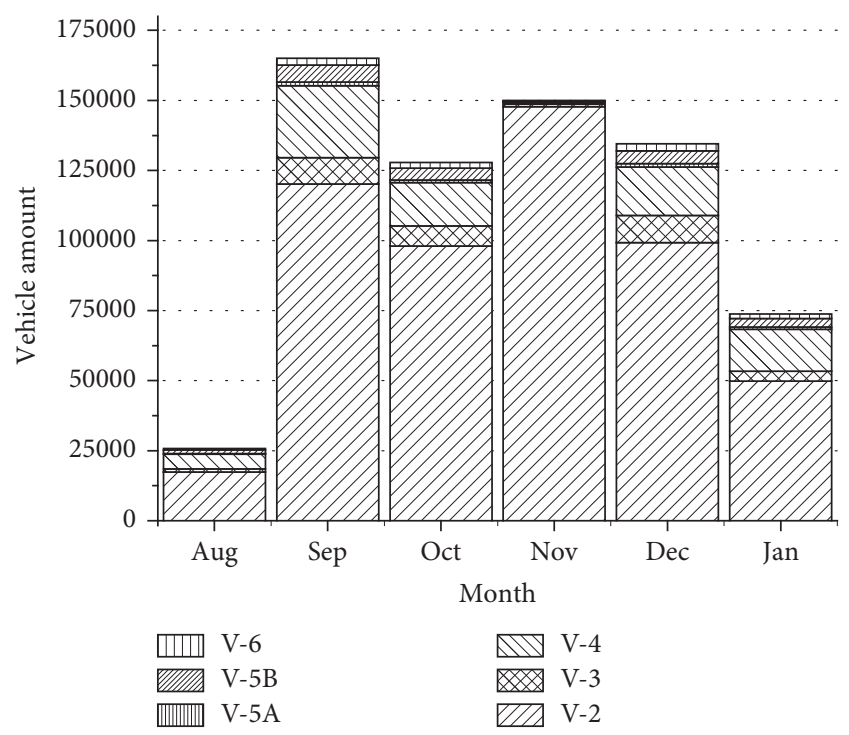

FIgURE 13: Statistical data of the heavy vehicle lane based on the traffic stream fatigue load.

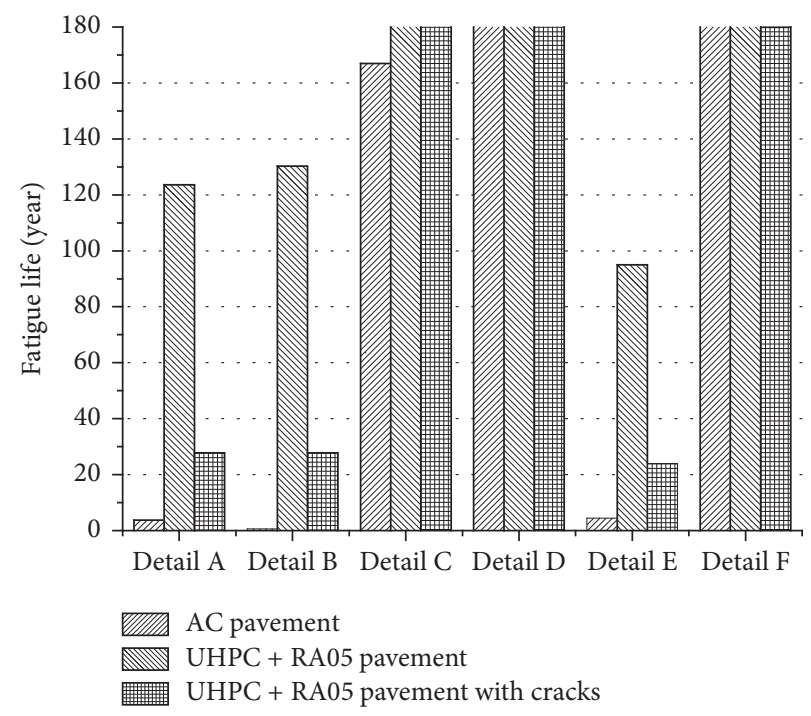

FIgURE 14: Fatigue lives of the critical regions.

increases from $7 \mathrm{~cm}$ to $22 \mathrm{~cm}$. The dead load is the critical factor in the pavement design, and it is not an effective and economical solution to reduce stress range by increasing the thickness of the AC pavement. Although the UHPC + RA05 pavement can perform well to reduce the stress range, the transverse stress increases rapidly when the elastic modulus of UHPC decreases to less than $50 \%$ of the original value. In Figure 15(b), the stress in the deck is sensitive to the thickness of the steel deck, and it reduces from $129 \mathrm{MPa}$ to $30 \mathrm{MPa}$ when the thickness of the steel deck increases from $12 \mathrm{~mm}$ to $28 \mathrm{~mm}$. Therefore, the fatigue performance of Detail B can be improved considerably by employing the UHPC layer or a thick steel deck. 


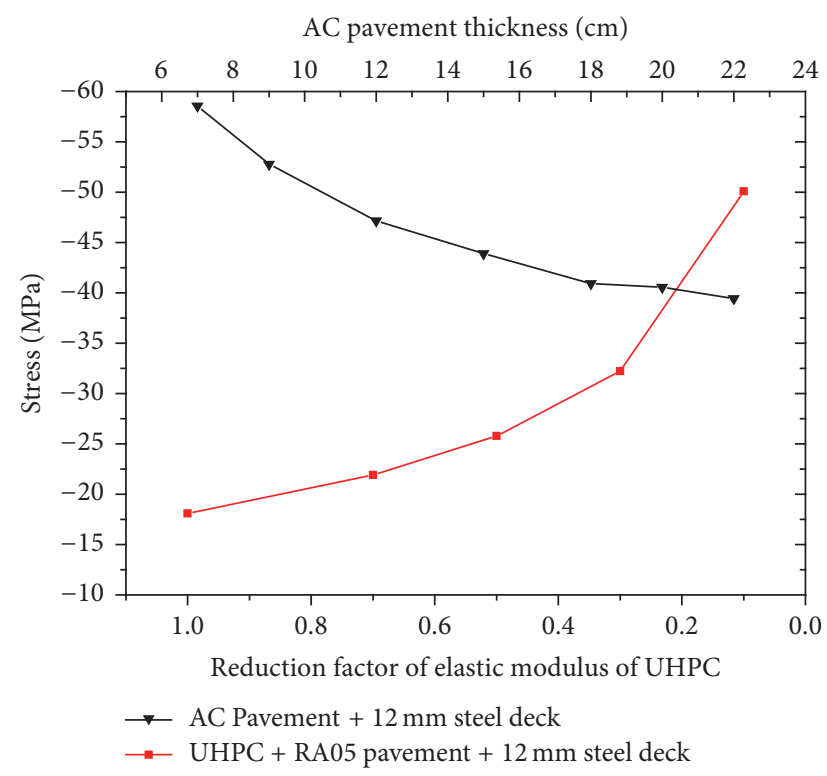

(a)

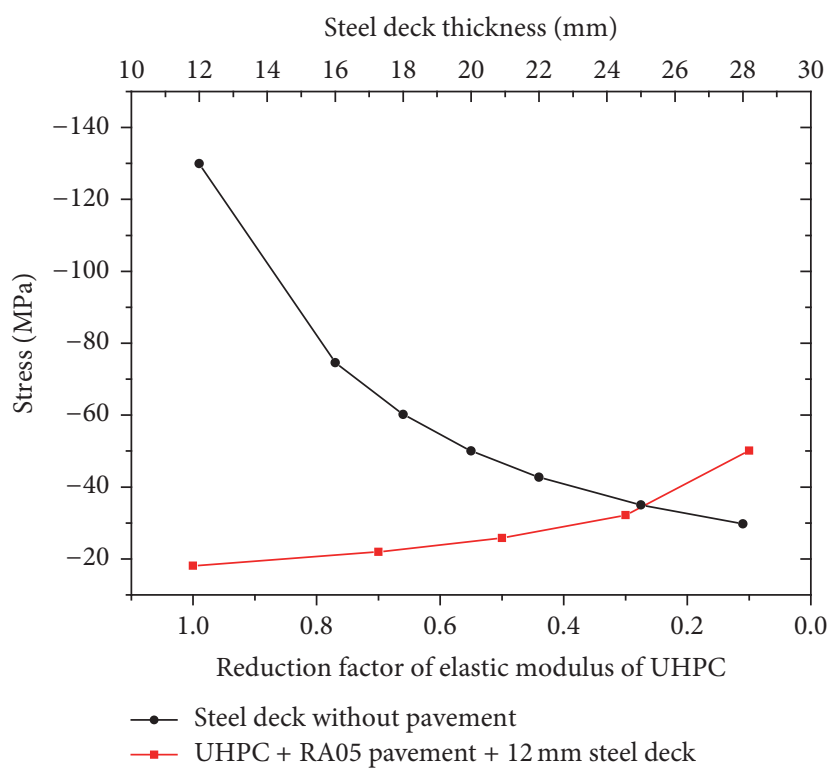

(b)

FIgURe 15: Parametric study on the transverse stress at Detail B.

\section{Conclusions}

A new pavement made of UHPC and RA05 is proposed in this paper. Results show that it is an effective method to improve the fatigue performance of the orthotropic steel deck. It is proved that the peak value of the stress distribution in the deck is reduced noticeably by using the UHPC + RA05 pavement, and then the fatigue lives of critical areas are studied by Miner's linear accumulative method. The following conclusions can be drawn:

(1) The pavement plays a key role in dispersing the axle load, so the stress ranges at fatigue sensitive details can increase significantly due to the failure or cracking of the pavement.

(2) Compared with the transverse stress distribution of the deck in the middle span of diaphragms, the stress distribution adjacent to the diaphragm location is much higher.

(3) The UHPC + RA05 pavement can improve the fatigue lives of details significantly. Fatigue lives of all the concerned details can exceed over 100 years except Detail E. However, fatigue lives decrease considerably after the elastic modulus of the UHPC + RA05 pavement reduces to $50 \%$ due to cracks.

(4) It is not an effective solution to reduce the stress range of fatigue sensitive details by increasing the thickness of the common asphalt concrete pavement. The fatigue performance of critical areas can be improved considerably by employing the UHPC layer or a relatively thick steel deck.

\section{Disclosure}

Part of the work in this paper was presented in Conference IALCCE 2016.

\section{Conflicts of Interest}

The authors declare that they have no conflicts of interest.

\section{Acknowledgments}

The authors would like to thank the National Key Basic Research and Development Plan (Program no. 2013CB036303), the National Natural Science Foundation of China (Program no. 51408424), and the Fundamental Research Funds for the Central Universities (2014KJ001) for financial support of this research.

\section{References}

[1] M. Lwin, "The FHWA manual for design, construction and maintenance of orthotropic steel deck bridges," in Proceedings of the 4th Orthotropic Bridge Conference, Tianjin, China, 2015.

[2] $\mathrm{W} . \mathrm{Xu}$ and $\mathrm{X} . \mathrm{N}$. Zhang, "Analysis of distress characters and design of steel orthotropic bridge," in Proceedings of the 2nd International Orthotropic Bridge Conference, pp. 184-192, Sacramento, Calif, USA, 2008.

[3] Y. F. Wang, C. P. Wang, and C. Y. Zhuang, "Research on temperature dependent dynamic modulus of asphalt mixture," Journal of Highway China Abroad, vol. 32, no. 2, pp. 210-214, 2012.

[4] X. Shao, D. Yi, Z. Huang, H. Zhao, B. Chen, and M. Liu, "Basic performance of the composite deck system composed of 
orthotropic steel deck and ultrathin RPC layer," Journal of Bridge Engineering, vol. 18, no. 5, pp. 417-428, 2013.

[5] S. L. Wang and Y. Zhang, "Impact of STC composite steel deck system to performance of orthotropic bridge deck," in Proceedings of the 4th Orthotropic Bridge Conference, Tianjin, China, 2015.

[6] L. Dieng, P. Marchand, F. Gomes, C. Tessier, and F. Toutlemonde, "Use of UHPFRC overlay to reduce stresses in orthotropic steel decks," Journal of Constructional Steel Research, vol. 89, pp. 30-41, 2013.

[7] R. Walter, J. F. Olesen, H. Stang, and T. Vejrum, "Analysis of an orthotropic deck stiffened with a cement-based overlay," Journal of Bridge Engineering, vol. 12, no. 3, pp. 350-363, 2007.

[8] Nanjing Second Yangze River Bridge Construction Headquarters-Southeast University, The Research on Epoxy Steel Deck Pavement of Nanjing Second Yangze River Bridge, School of Transportation of Southeast University, Nanjing, China, 2001.

[9] J. Li, X.-T. Feng, X.-D. Shao, Y. Wang, and J.-H. Cao, “Comparison of mechanical calculation and actual test for new STC steel bridge paving system," China Journal of Highway and Transport, vol. 27, no. 3, pp. 39-44, 2014.

[10] B. Ji, R. Liu, C. Chen, H. Maeno, and X. Chen, "Evaluation on root-deck fatigue of orthotropic steel bridge deck," Journal of Constructional Steel Research, vol. 90, pp. 174-183, 2013.

[11] Ministry of Transport of the People's Republic of China, General Code for Design of Highway Bridges and Culverts (JTG D602004), China Communications Press, Beijing, China, 2004.

[12] M. H. Kolstein, Fatigue classification of welded joints in orthotropic steel bridge decks [Ph.D. thesis], Delft University of Technology, Delft, The Netherlands, 2007.

[13] Z.-G. Xiao, K. Yamada, S. Ya, and X.-L. Zhao, "Stress analyses and fatigue evaluation of rib-to-deck joints in steel orthotropic decks," International Journal of Fatigue, vol. 30, no. 8, pp. 13871397, 2008.

[14] A. Nussbaumer, L. Borges, and L. Davaine, Fatigue Design of Steel and Composite Structure, ECCS, Berlin, Germany, 2011.

[15] C. Wu, "Fatigue load models for orthotropic deck of steel bridge in China," in Proceedings of the 4th Orthotropic Bridge Conference, Tianjin, China, 2015.

[16] E. S. Lappa, High strength fibre reinforced concrete static and fatigue behaviour in bending [Ph.D. dissertation], Delft University of Technology, Delft, The Netherlands, 2007.

[17] T. Makita and E. Brühwiler, "Damage models for UHPFRC and R-UHPFRC tensile fatigue behaviour," Engineering Structures, vol. 90, pp. 61-70, 2015.

[18] Z. Yu, M. An, and G. Yan, "Experimental research on the fatigue performance of reactive powder concrete," China Railway Science, vol. 29, no. 4, pp. 35-40, 2008.

[19] Eurocode 3: Design of Steel Structures Part 1-9: Fatigue, ENV 1993-1-9, 2005. 


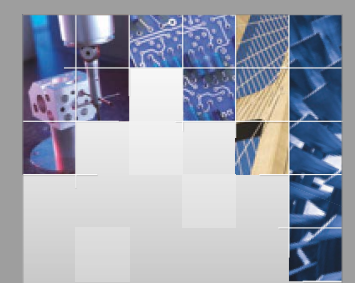

\section{Enfincering}
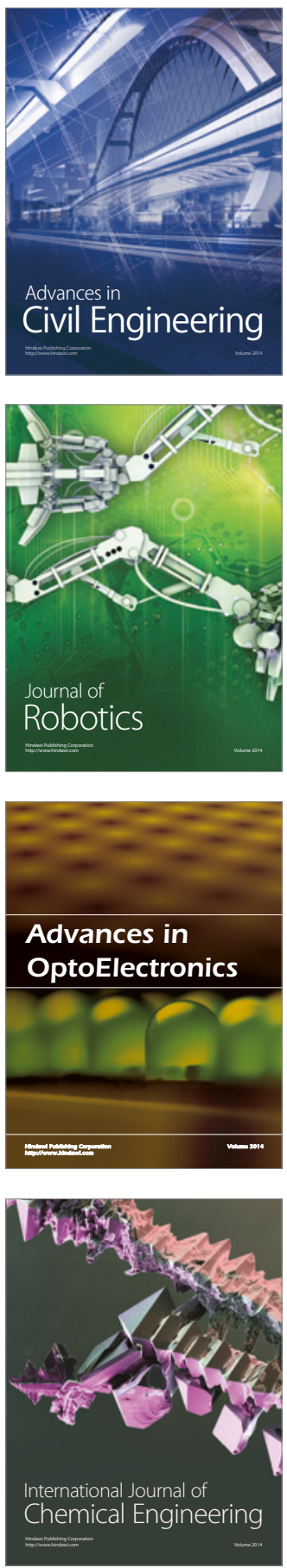

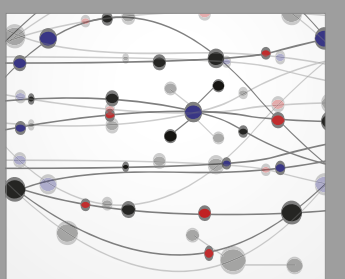

The Scientific World Journal

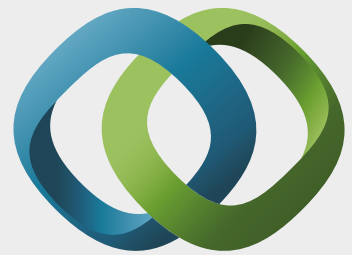

\section{Hindawi}

Submit your manuscripts at

https://www.hindawi.com
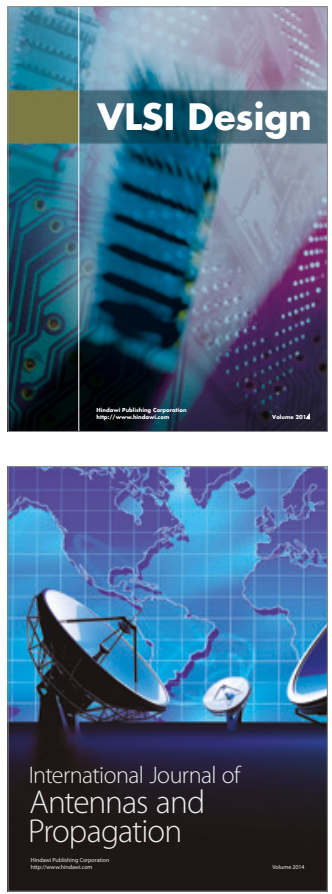

\section{Rotating}

Machinery
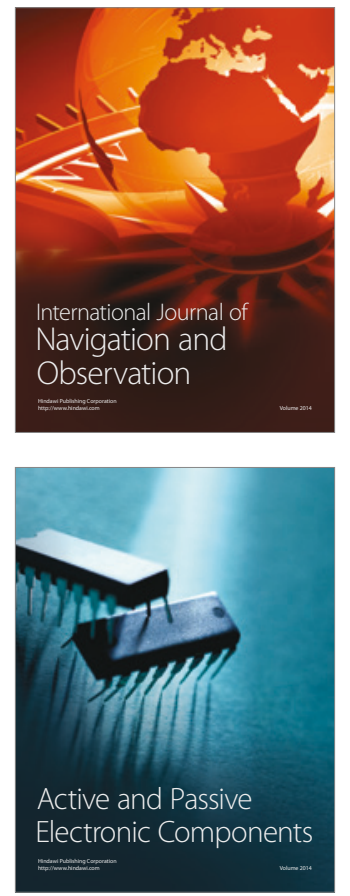
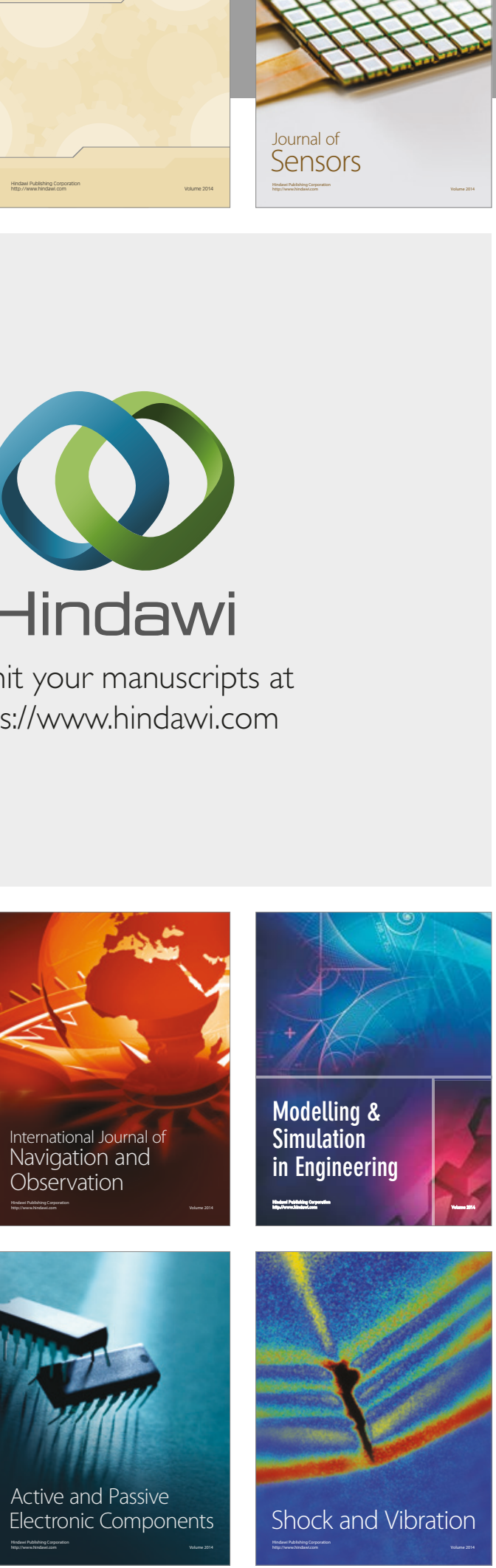
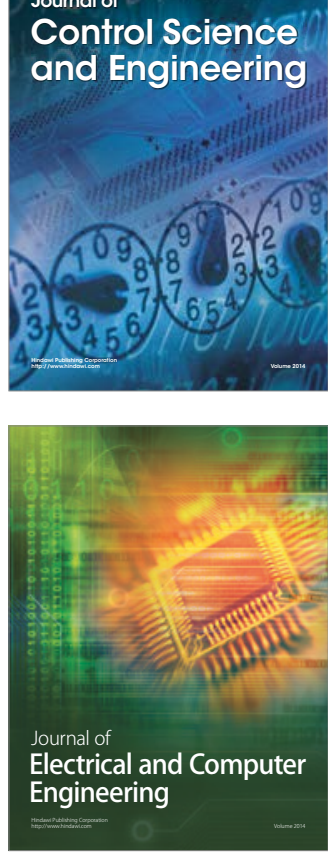

Distributed

Journal of

Control Science

and Engineering
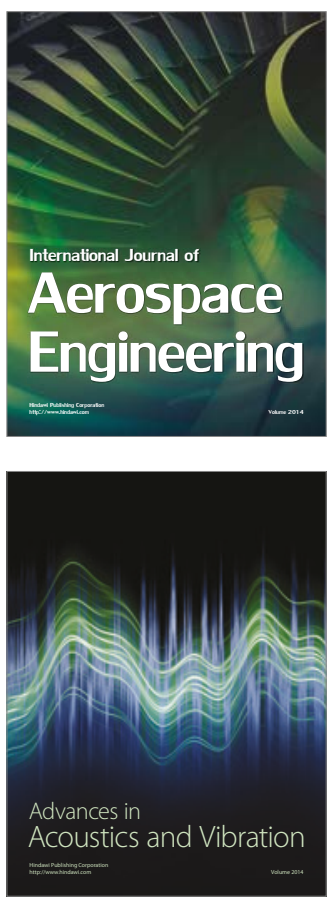

Sensor Networks 